\title{
Comparison of Different Microcontrollers Used for Bluetooth based Home Robotization
}

\author{
S. Naga Mallik Raj ${ }^{1}$, S. Neeraja ${ }^{2}$ \\ ${ }^{1}$ Department of CSE, Vignan's Institute of Information Technology, \\ Visakhapatnam, AP, India \\ ${ }^{2}$ Department of CSE, Pydah College of Engineering and Technology, Visakhapatnam, \\ $A P$, India \\ mallikblue@gmail.com,neerajasreerama@gmail.com
}

\begin{abstract}
A microcontroller is a little and negligible exertion PC that attempts to manage specific errands. The basic level describes this as piece of things that require a level of control to be associated by the client. Today phenomenal sorts of microcontrollers are open with various word lengths, for example, 8bit, 16bit, 32bit, etc. It is a compacted microcomputer fabricated to control the segments of presented structures in home mechanical congregations. The purpose of this paper is to give the fundamental information of microcontroller and relative examination of 8051 Microcontroller, ARM Microcontroller, PIC Microcontroller and AVR Microcontroller and furthermore this paper emphasizes on the details of various HAS Technologies, through which users can select the best technology for their requirement. This paper exhibits the course of action and execution of an insignificant effort yet flexible and secure versatile Bluetooth HAS. The blueprint relies upon a stay lone ATmega16 microcontroller. It will control Home pack machines and provides home security. ${ }^{1}$
\end{abstract}

Keywords: Microcontroller, ARM, PIC, AVR, Home robotization, Bluetooth

\section{INTRODUCTION}

This paper additionally discusses about the examination of some well known home computerization systems and features their favorable circumstances, downsides and furthermore different Comparisons between different Microcontrollers [1].

Let us discuss different comparisons between different Microcontrollers.

Table 1. Comparisons between different Microcontrollers

\begin{tabular}{|c|c|c|c|c|}
\hline BUS WIDTH & $\mathbf{8 0 5 1}$ & PIC & AVR & ARM \\
\hline $\begin{array}{c}\text { 8- bit for } \\
\text { standard core }\end{array}$ & $\begin{array}{c}8 / 16 / 32- \\
\text { bit }\end{array}$ & $8 / 32$ bit & $\begin{array}{c}32 \text { bit mostly also } \\
\text { available in } 64 \text { bit }\end{array}$ \\
\hline $\begin{array}{c}\text { Communication } \\
\text { Protocols }\end{array}$ & UART & $\begin{array}{c}\text { UART, } \\
\text { LIN,ETHE } \\
\text { RNET }\end{array}$ & $\begin{array}{c}\text { UART, SPI, USB, } \\
\text { ETHERNET }\end{array}$ & $\begin{array}{c}\text { UART, SPI, USB, } \\
\text { ETHERNET, } \\
\text { SAI,IrDA }\end{array}$ \\
\hline
\end{tabular}

Article history:

Received (September 14, 2018), Review Result (October 21, 2018), Accepted (March 22, 2019) 


\begin{tabular}{|c|c|c|c|c|}
\hline MEMORY & $\begin{array}{c}\text { ROM, } \\
\text { SRAM, } \\
\text { FLASH }\end{array}$ & $\begin{array}{c}\text { SRAM,FL } \\
\text { ASH }\end{array}$ & SRAM,EEPROM & $\begin{array}{c}\text { FLASH,SDRAM,EE } \\
\text { PROM }\end{array}$ \\
\hline ISA & CLSC & RISC & RISC & RISC \\
\hline $\begin{array}{c}\text { POWER } \\
\text { CONSUMPTION }\end{array}$ & AVERAGE & LOW & LOW & LOW \\
\hline COMMUNITY & VAST & $\begin{array}{c}\text { VERY } \\
\text { GOOD }\end{array}$ & VERY GOOD & VAST \\
\hline
\end{tabular}

Table 2. The accompanying table looks at the previously mentioned AVR arrangement of microcontrollers

\begin{tabular}{|c|c|c|c|}
\hline Series Name & Pins & Flash Memory & Special Feature \\
\hline TinyAVR & $6-32$ & $0.5-8 \mathrm{~KB}$ & Small in size \\
\hline MegaAVR & $28-100$ & $4-256 \mathrm{~KB}$ & Extended peripherals \\
\hline XemaAVR & $44-100$ & $8-384 \mathrm{~KB}$ & DMA \\
\hline
\end{tabular}

\section{WHAT'S SPECIAL ABOUT AVR?}

They are quick: AVR microcontroller executes a large portion of the directions in single execution cycle. AVRs are 4 times speedier than PICs, they spend less power and can be worked in various power sparing modes[1][2].

Table 3. Comparison between the three most commonly used families of microcontrollers

\begin{tabular}{|c|c|c|c|}
\hline Description & $\mathbf{8 0 5 1}$ & PIC & AVR \\
\hline SPEED & SLOW & MODERATE & FAST \\
\hline MEMORY & SMALL & LARGE & LARGE \\
\hline ARCHITECTURE & CISC & RISC & RISC \\
\hline TIMERS & INBUILT & INBUILT & INBUILT \\
\hline
\end{tabular}

\section{WHAT IS HOME ROBOTIZATION?}

Home robotization is defined as the one which controls each and every single electrical gadget in our home or office. Debilitated can give stretched out individual satisfaction to people who may by one means or another require parental figures or institutional care.

\subsection{HIGHLIGHTS AND BENEFITS OF HOME ROBOTIZATION}

\subsubsection{HIGHLIGHT OF HOME ROBOTIZATION}

(1). Interoperability 
It is the capacity to entwine different electronic gadgets so they can execute as one framework. A decent case of interoperability is having the lights kill, the fans kill and sends you a content that somebody has intruded in to your room while you are away.

\section{(2). Access from far away}

"Mechanization is tied in with having the capacity to control things in your home," says Jay McClellan, leader of Home Automation Inc. So we can Access our Home gadgets from far away ( i.e upto some meters ).

\section{(3). Assortment of Interfaces}

There are various diverse ways you can control the electronic frameworks in your home: by squeezing the catches of a handheld remote or divider mounted keypad, by touching bright symbols on a compact touch board

\section{(4). Can-do Attitude}

Mechanization is just useful and handy on the off chance that fits your way of life. Since everybody's way of life is extraordinary, the maker ought to give its installer the apparatus to tweak the framework to your particular needs.

\section{(5). Expandability}

Innovation will keep on evolving, presenting a totally new age of items to the commercial center. Later on, you may likewise need to include new rooms. it's essential that a home computerization framework can be effortlessly extended both vertically to fuse extra items and evenly to help extra rooms.

\section{(6). Upgradeability}

Before you purchase any framework, make sure the maker (or your installer) will have the capacity to open and download programming refreshes naturally.

\subsection{ADVANTAGES OF HOME ROBOTIZATION}

\section{Includes Safety through Appliance and Lighting Control}

Just by selecting the Bluetooth options in our phone, we can control all appliances .This further enhances the well being and security of your home[1][2][3].

\section{Saves Money \& Increases Convenience}

By this technology we can save power, money and time. And it is more convenient.

\section{Expands Peace of Mind}

In our daily routine works, we get tensed about our gadgets at home after the door lock so this technology monitors the status and ensures security. 


\section{VARIOUS HAS TECHNOLOGIES}

\subsection{Bluetooth based home automation system}

(1). It's safe.

(2). Easy to utilize.

(3). It works in short separation range(i.e. upto 10mtrs.) 4. Anybody can find free Bluetooth applications on android and some more If you ask me, why I made this task?? My answer would be basic since I am far excessively languid and need, making it impossible to control things sitting at one place. It was shown in below figure.

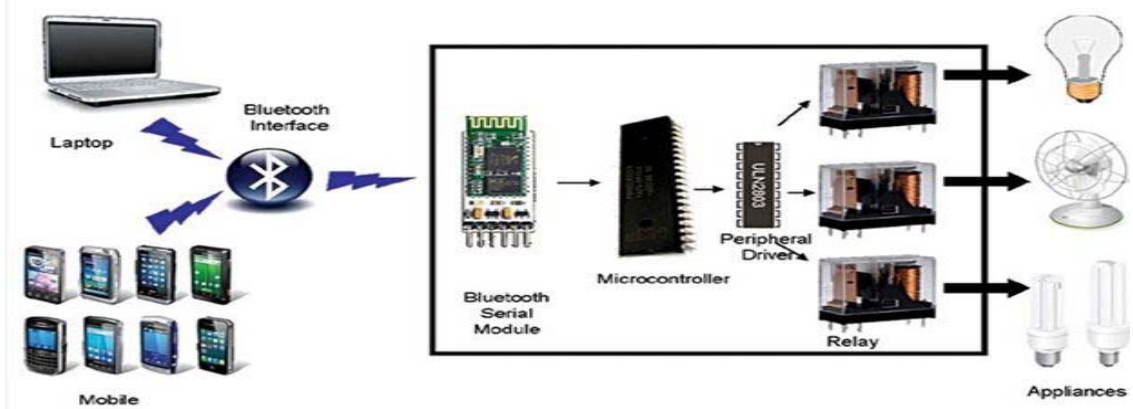

Figure 1. Block Diagram[1]

\subsection{Voice acknowledgment based HAS}

The voice is caught through a receiver, inspected, shifted and changed over to computerized information with a simple to-advanced converter. The information is then compacted and sent serially as parcels of double information. At less than desirable end (Central Controller Module), double information has been changed over to simple, separated and go to the PC through the sound card. A Visual Basic application program, running on the PC, utilizes Microsoft Speech API library for the voice acknowledgment. Endless supply of the summons, control characters are sent remotely to the predetermined apparatus address. Thus, apparatuses' can be turned ON or OFF contingent upon the control characters got.

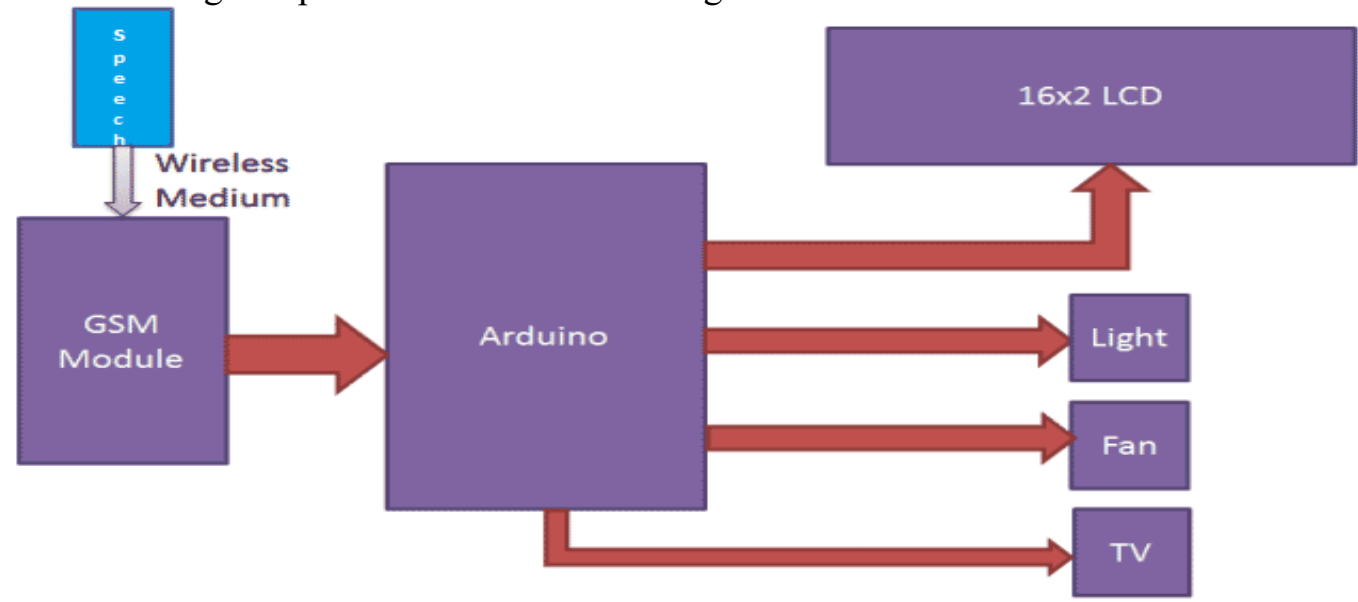

Figure 2. Block Diagram of Voice acknowledgment based HAS [2] 


\subsection{ZigBee Based Wireless HAS}

Zigbee convention is the correspondence convention that is utilized as a part of this framework. Zigbee offers $250 \mathrm{kbps}$ as the most extreme baud rate, nonetheless, $115200 \mathrm{bps}$ was utilized for sending and accepting, as this was the most noteworthy speed that the UART of the microcontroller could be customized to work at. ZigBee incorporates vitality recognition, clear channel evaluation and channel deftness, which enables gadgets to pick the most ideal channel and stay away from different remote systems, for example, Wi-Fi ${ }^{\circledR}$ while message affirmation guarantees the information was conveyed to its goal. Various levels of security guarantee that the system and information stay in place and secure. One of ZigBee's key highlights is its capacity to cover vast territories with switches. This component separates ZigBee from different advances. Work organizing broadens the scope of the system through directing, while self recuperating builds the unwavering quality of the system by re-steering a message in the event of a hub disappointment.

\subsection{GSM Based Home Automation System}

Arduino is utilized for controlling the entire procedure. Here we have utilized GSM remote correspondence for controlling home machines. We send a few orders like "\#A. light on*", "\#A. light off*" etc for controlling AC home apparatuses'. Subsequent to accepting given orders by Arduino through GSM, Arduino sends flag to transfers, to turn ON or OFF the home machines utilizing a hand-off driver[4].

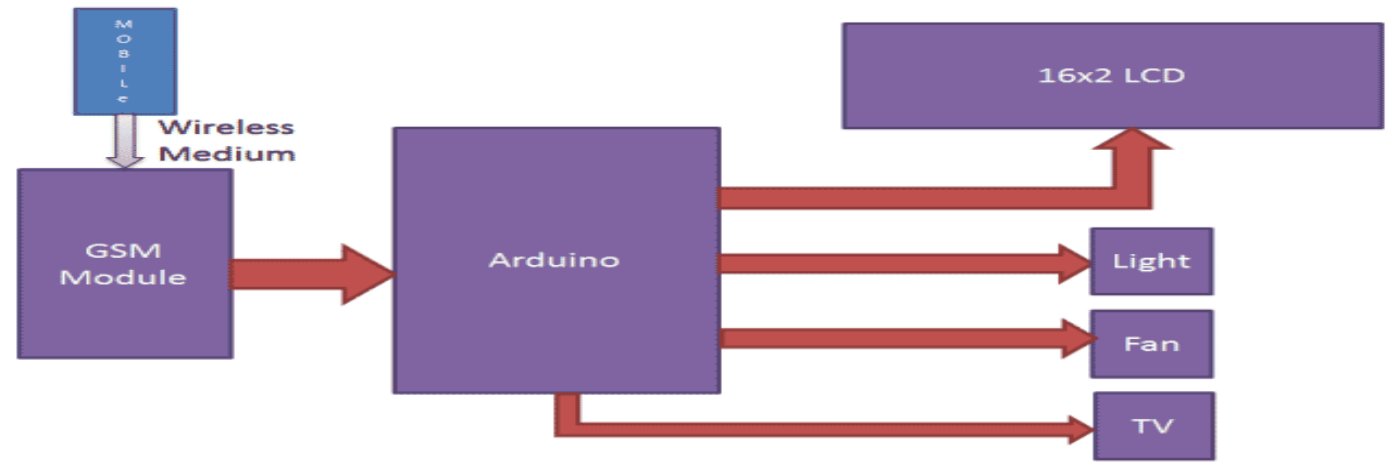

Figure 3. Block Diagram of GSM Based Home Automation System [3]

\subsection{Internet of things (IoT) based HAS}

The fundamental segments and materials for home mechanization utilizing IOT venture can be recorded as a Wi-Fi module, Opto-coupler, TRIAC, resistors, capacitors, diode, controller, loads (home apparatuses). There are different eCommerce sites that are giving offices to buy all the required segments online, for example, an undertaking pack comprising of individual segments basic to outline a specific task from www.edgefxkits.com, Edgefx additionally offers instant unit fitting and play compose venture units and (Do It Yourself) DIY venture packs for designing understudies and electronic specialists. The home computerization utilizing IOT venture comprises of different squares, for example, control supply, Optocoupler, WiFi module, TRIAC, voltage controller, SMPS (Switch Mode Power Supply) and load. 


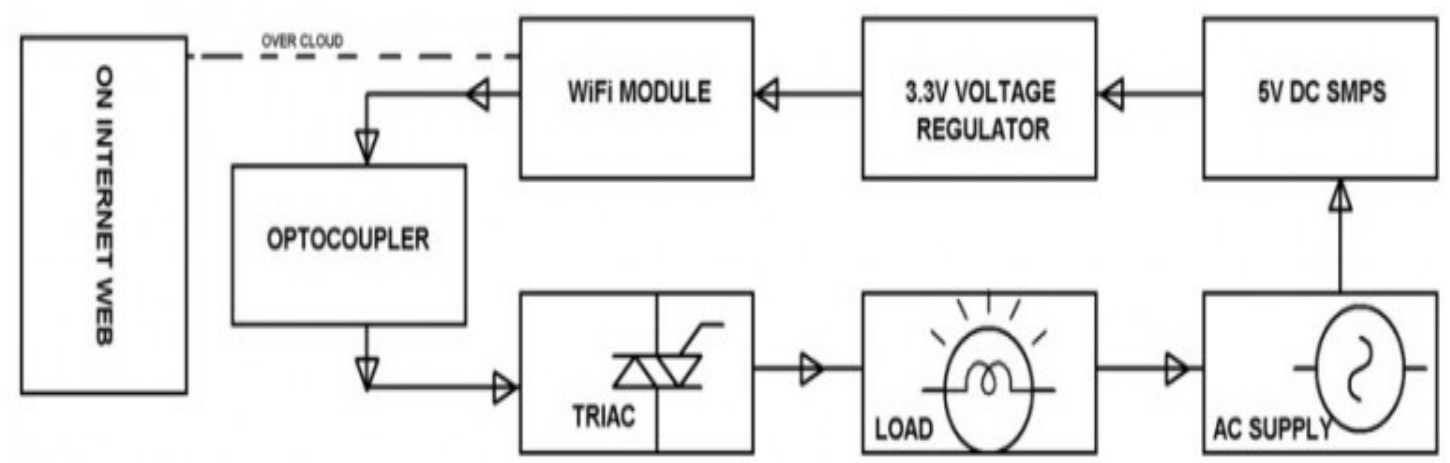

Figure 4. Block Diagram of Internet of things (IoT) based HAS [4]

\subsection{EXAMINATION OF DIFFERENT HAS}

Table 4. Examination of Different HAS

\begin{tabular}{|c|c|c|c|}
\hline System & Cost & Speed & Real time \\
\hline Blutooth & Low & High & Yes \\
\hline Voice Recognition & Low & High & Yes \\
\hline ZigBee & Low & High & Yes \\
\hline GSM & High & Slow & No \\
\hline Internet, Wi-Fi & High & Slow & Yes \\
\hline
\end{tabular}

Based on the above discussion we selected Bluetooth based HAS as a good one to Control Home apparatus, with Atmega16 microcontroller.

\section{CIRCUIT DESCRIPTION}

\subsection{ATmega16 MICROCONTROLLER}

ATmega16 is the cerebrum of the undertaking. It controls the general action of the venture. It consumes Low power. It depends on improved RISC design with 131 intense guidelines. The ATmega 16, being an AVR center, can execute up to 16 million direction for each second. This is because of the way that AVR guidelines are executed on a solitary clock[1][2][4] . 


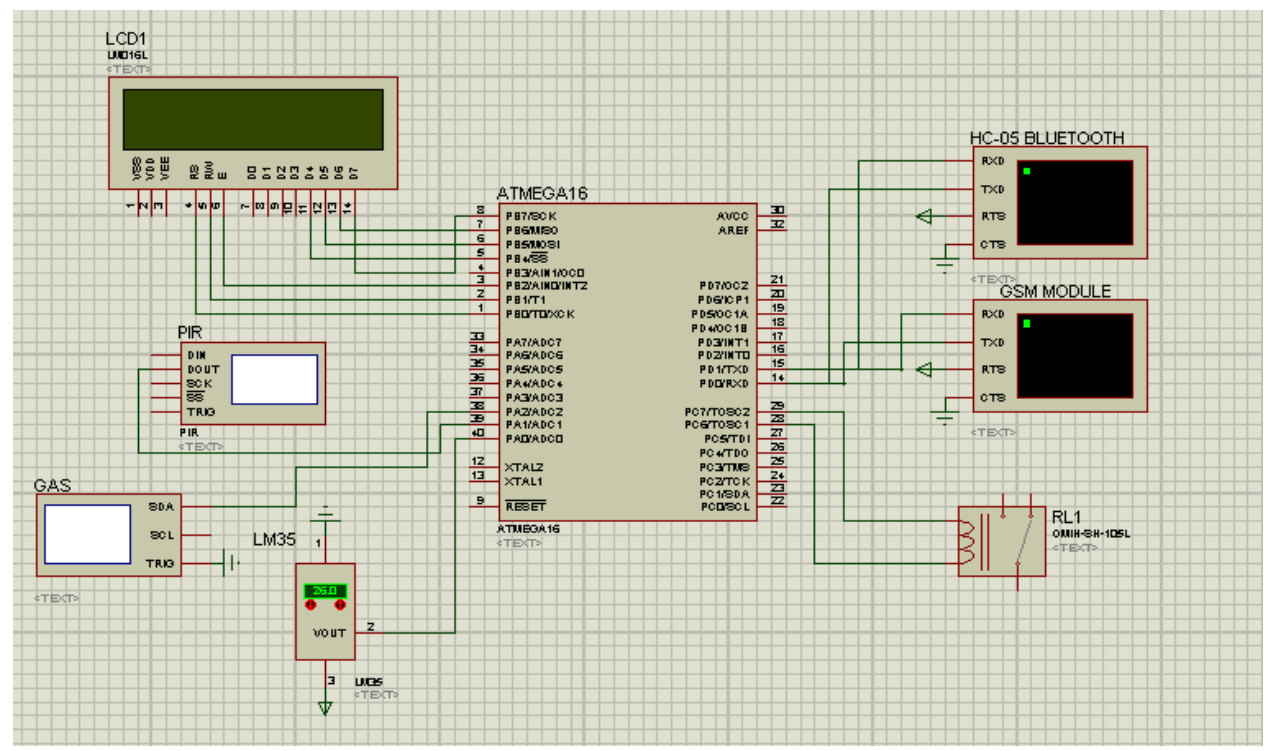

Figure 4. Circuit Diagram [2]

ATmega16 has different in-manufactured peripherals.

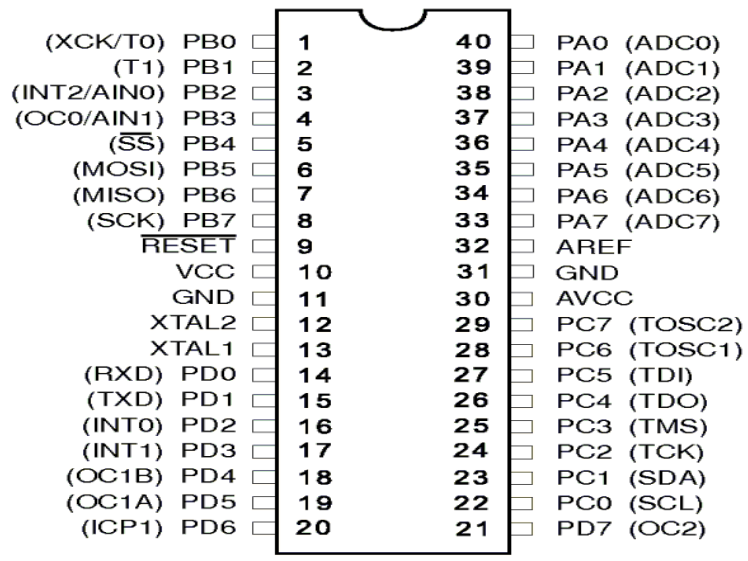

\section{Figure 5. ATmega16 Pins[1]}

\section{Ports:}

- Atmega16 has four ports namely PORTA, PORTB, PORTC and PORTD

- All ports have Read-Modify-Write usefulness.

- All pins are equipped for performing double capacities!

\section{Registers:}

- Each port pin has three register bits
1. DDRx
2. PORTx 3. PINx 


\section{DDRx}

- $\quad$ DDRx $=0 x f f ; / /$ configuring as $\mathrm{o} / \mathrm{p}$

- $\quad \operatorname{DDRx}=0 \mathrm{x} 00 ; / /$ configuring as $\mathrm{i} / \mathrm{p}$

\section{PINx :: To Read data}

When sensor is connected to a least significant bit of Port D. To read the status of the sensor, we use PIND.i.e., $\mathrm{x}=\mathrm{PIND}$; / $\mathrm{x}$ acquires the status of port $\mathrm{D}$

$$
\begin{aligned}
& \text { if }(x \& 0 b 00000001) \\
& \{\text { sensor is } \mathrm{ON}\} \\
& \text { else } \\
& \text { ssensor is OFF }
\end{aligned}
$$

\subsection{6x2 LCD}

Liquid crystal display used to display data from the microcontroller. I use 16x2 LCD and can display 32 characters in two lines. The $16 \times 2$ LCD has 16 pins.

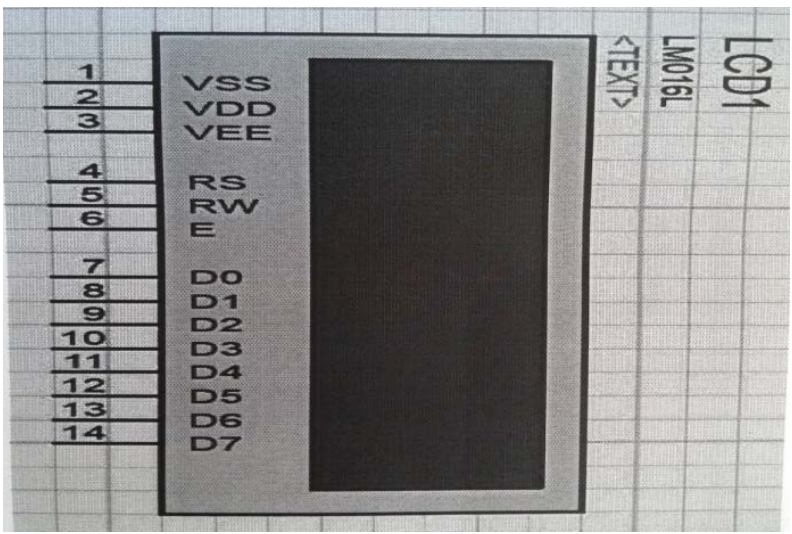

Figure 6. 16x2 LCD Pins [3]

\subsection{MQ7}

MQ7 is a gas sensor which mainly detects carbon-monoxide and smoke. The sensor has 3 pins VDD, Data and GND which are connected to $+5 \mathrm{v}$, data pin and GND of microcontroller.

Table 5. MQ7 Pins

\begin{tabular}{|c|c|c|}
\hline Pin No: & Symbol & Description \\
\hline 1 & VDD & Power pin \\
\hline 2 & DATA & $\begin{array}{c}\text { Data pin, it takes the input and the } \\
\text { microcontroller calibrates for gas or } \\
\text { smoke }\end{array}$ \\
\hline 3 & GND & Ground pin \\
\hline
\end{tabular}




\subsection{PIR}

This sensor is used to detect any motion. The sensor has 3 pins VCC, OUT and GND

Table 6. PIR Pins

\begin{tabular}{|l|l|l|}
\hline Pin No: & Symbol & Description \\
\hline 1 & VCC & Power pin \\
\hline 2 & OUT & $\begin{array}{c}\text { OUT pin, detects and send any } \\
\text { motion }\end{array}$ \\
\hline 3 & GND & Ground pin \\
\hline
\end{tabular}

\section{HARDWARE DESIGN}

The project uses the following hardware components:

- Microcontroller

- GSM module

- HC-05 Bluetooth Module

- LCD

- LM35

- MQ7

- PIR

- Relay

The other components used are:

- LED

- Variable Resister

- Jumping wires

- Voltage regulator

- Capacitor

\subsection{MICROCONTROLLER}

A microcontroller is a little, minimal effort PC that includes:

- 16 bit microprocessor(CPU), RAM , ROM ,

- Parallel or potentially serial I/O, flag

- $\mathrm{A} / \mathrm{D}$ and/or $\mathrm{D} / \mathrm{A}$ conversion

- To operate a gadget we have to run the code.

\subsection{ATMEGA16}


Since I'm using TechieNest development board, this device uses Atmega16 as an IC. ATmega16 is produced by ATMEL Company. All necessary information about this microcontroller is stated in the datasheet which is produced by ATMEL.

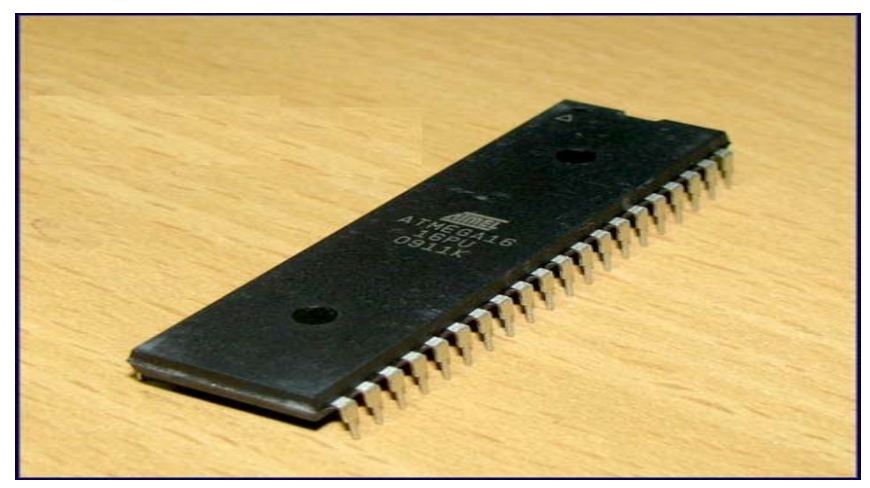

Figure 7. ATmega16 [1]

\section{ALGORITHM}

- The structure captures the rules in ASCII format from the Bluetooth engaged Android mobile phone using the Bluetooth module and passes it on to the scaled down scale controller.

- The scaled down scale controller does the central dealing which requires the code.

- What happens when the controller gets a particular ASCII regard it kills ON or an exchange.

- Moreover, the exchange goes about as a switch for AC contraptions.

- I have used some pennant factors which check whether a particular hand-off is ON or OFF.

- A particular ASCII regard is dispensed for one and only a solitary hand-off.

- Right when an ASCII regard is enjoyed a reprieve, it switches ON the exchange.

\section{RESULTS}

In fig. 8 menu screenshot. In that with the Bluetooth we can see the status of the lights, security, door, gas, etc. In fig. 9 for example if we want to check the lights status, here in living room the lights were ON. If we want OFF the light we can do it. In outdoor it is in OFF, if we want to $\mathrm{ON}$, we can do it from outside. 


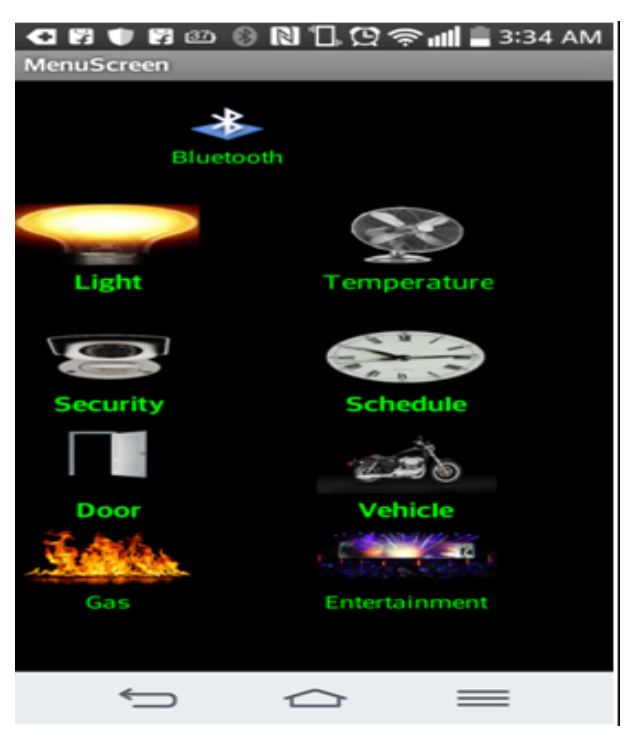

Figure 8. Menu Screenshot

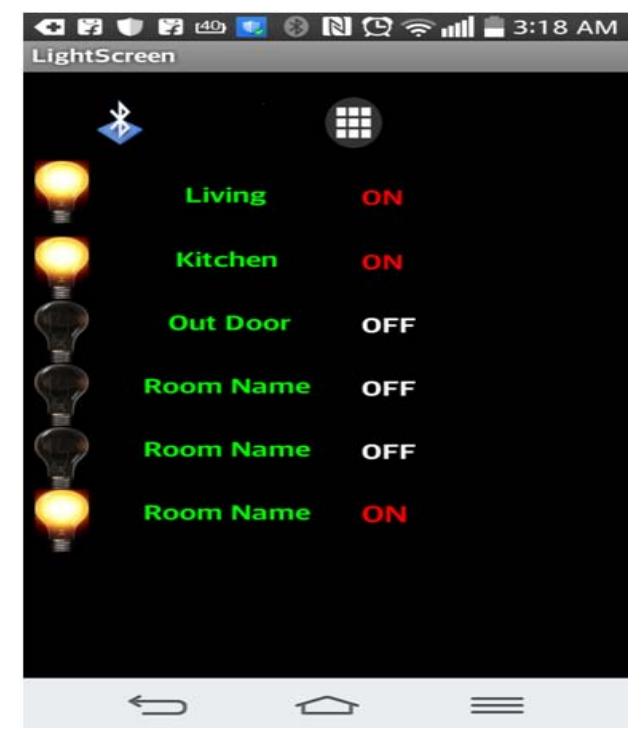

Figure 9. Light Control Screenshot

\section{FUTURE ENHANCEMENTS}

As a future work, this endeavor can be used as a sort of point of view or as a base for understanding an arrangement to be executed in various errands of more essential level by growing the security part, versatile, and even lower cost. The endeavor can be updated by recording video and using face recognizer with the goal that in any case the interloper can be recognized successfully.

\section{CONCLUSION}

In this paper different home automation systems and various microcontrollers with their pros and cons are discussed. I have demonstrated conceivable use of Bluetooth based home computerization structure which is having negligible exertion, secured and generally accessible. 
By controlling the lights, fans, warmers and other home apparatuses' remotely we can spare our cash, vitality and time. From this framework we can likewise get adaptability, reasonability and accomplish security. For elderly and impaired population this framework assumes an extraordinary part.

\section{REFERENCES}

[1] N. Sriskanthan and Tan Karand, "Bluetooth Based Home Automation System", Journal of Microprocessors and Microsystems, Vol. 26, pp.281-289, (2002). [DOI: 10.1016/s0141-9331(02)00039-x]

[2] Huiping Huang, Shide Xiao, Xiangyin Meng and Ying Xiong, "A Remote Home Security System Based on Wireless Sensor Network and GSM Technology”, Second International Conference on Networks Security Wireless Communications and Trusted Computing 2010, vol 1, pp. 535-538, April (2010). [DOI: 10.1109/NSWCTC.2010.132]

[3] Carelin Felix and I. Jacob Raglend, "Home Automation Using GSM", Proceedings of 2011 International Conference on Signal Processing, Communication, Computing and Networking Technologies, pp. 15-19, (2011).[DOI: 10.1109/ICSCCN.2011.6024506]

[4] Wijetunge, S.P., Wijetunge, U.S.; Peiris G.R.V., Aluthgedara C.S. and Samarasinghe A.T.L.K., "Design and Implementation of a Bluetooth based General Purpose Controlling Module", 4th International Conference on Information and Automation for Sustainability. (2008) [DOI: 10.1109/ICIAFS.2008.4783997]

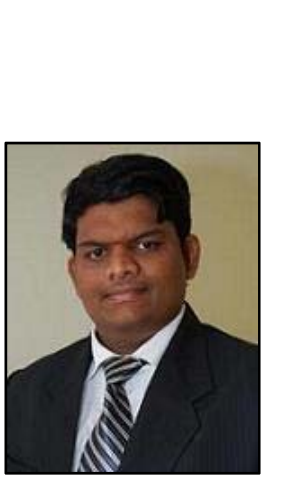

\section{Authors}

Received his B. Tech in CSE from Jawaharlal Nehru Technological University, Hyderabad, Andhra Pradesh, India. He Completed his M. Tech from Jawaharlal Nehru Technological University, Hyderabad, Andhra Pradesh, India. Currently he is working as Asst. Prof in Department of CSE, Vignan's Institute of Information Technology, Vizag, Andhra Pradesh, India. He Published more than 10 publications. pursuing ph.D in Computer Science \& Multimedia, Lincoln University College, Malaysia .His research interests include Mobile Computing, Network security, Cryptography, etc.

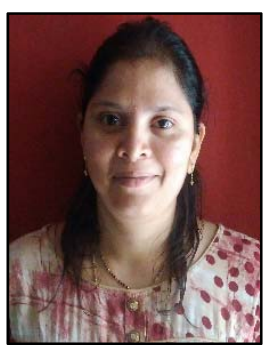

Received her B. Tech in CSE from Jawaharlal Nehru Technological University, Hyderabad, Andhra Pradesh, India. she Completed her M. Tech from Jawaharlal Nehru Technological University, Hyderabad, Andhra Pradesh, India. Currently she is working as Asst. Prof in Department of CSE, Pydah College of Engineering and Technology, Gambheeram, Vizag, Andhra Pradesh, India. she Published more than 10 publications. Her research interests include Mobile Computing, Network security, Cryptography, etc. 